\title{
Theoretical Study of the Lowest Energy Structure of the Water Undecamer
}

\author{
Han Myoung Lee \\ Center for Superfunctional Materials, Department of Chemistry. Pohang Lminersin of \\ Science and Technologv: Pohang 790-784, Korea \\ Received April 24, 2003
}

\begin{abstract}
Density functional calculations and $a b$ initio calculations have been carried out to study the lowest energy stnicture of the water $\left(\mathrm{H}_{2} \mathrm{O}\right)_{11}$. Among five structures suggested by four different groups. the lowest energy: stnicture is found to have the skeletal stnicture of Prism56 (Pr56-24) that a cyclic pentamer and a cyclic hexamer are fused into a prism-shape with 16 hydrogen-bonds (HBs).
\end{abstract}

Key Words : Water clusters. Undecamer, Hydrogen bond

\section{Introduction}

Snall water clusters $\left(\mathrm{H}_{2} \mathrm{O}\right)_{\mathrm{n}}$ have been extensively studied with tremendous experimental ${ }^{1, \hat{z}}$ and theoretical ${ }^{3 \cdot 15}$ efforts in the recent past. Studies of structures and energetics of water clusters are of iniportance for understanding various phenonena such as hydration by cations, ${ }^{16}$ anions. ${ }^{17}$ electrons. ${ }^{18}$ and organic/bio-molecules ${ }^{15}$ as well as various types of hydrogen bonding. ${ }^{\text {(i) }}$

Theoretically. at the early stage of low-level $a b$ initio calculations there were a few studies of the dimer and cyclic water trimer. ${ }^{3.4}$ The study of various low-lying energy confonmers for water clusters $\left(\mathrm{H}_{2} \mathrm{O}\right)_{4.8}$ was first reported using simulated annealing Monte Carlo method employing various $a b$ initio derived two-body to four-body interaction potentials and $a b$ initio methods. "These predicted nininium energy structures have been found to be in excellent agreement with the experintental findings. ${ }^{-}$Oving to the nature of several isoenergetic conformers of the water hexamer and heptamer responsible for the facile structural changes between two dimensional and three dimensional structures, these conformers have been extensively investigated. Very recently structures of the water dimer to dodecamer based on extensive $a b$ initio calculations have been reported. ${ }^{7.8}$

In the case of the undecamer. five global minimum energy structures have been reported by four different groups (Figure 1). ${ }^{8.13-15}$ These conformers have different skeletal structures. Since the five structures are different. it is of importance to find the true lowest energy structure.

As for the empirical studies of $\left(\mathrm{H}_{2} \mathrm{O}\right)_{11}$. Niesse and Mayne. ${ }^{13}$ on the basis of TIP3P potential reported that the lowest energy conformer of $\left(\mathrm{H}_{3} \mathrm{O}\right)_{11}$ is Pr56-134. a Prism56 skeletal shape fused by cyclic hexamer and pentamer. Wales and Hodges ${ }^{l 4}$ reported that the lowest energy structures based on the TIP4P potential is a Prism56. stnucture (which will be defined in our terminology as a fused structure with a pentagonal pentamer and an open-book-shape hexamer) and new lowest-energy confommer Pr56-13 on the TIP3P potential. Sadlej reported another structure (Prism 55+1) using HarteeFock calculations with $6-31 \mathrm{G}^{*}$ basis set. ${ }^{15}$ On the other hand. Kin and coworkers reported that the lowest energy structure is Pr56-24 based on various levels of theoretical methods. ${ }^{8}$ However, there was no direct comparison between Pr56-24 and Pr55+1. Furthermore, Sobolewski and Doncke in their study of the water undecamer use Sadlej's structure as the lowest energy conformer. ${ }^{15}$ Therefore. the structure of $\left(\mathrm{H}_{2} \mathrm{O}\right)_{11,12}$ is controversial.

Since no direct comparison of the five structures based on reliable $a b$ initio energetics has been made yet. here we compare six structures including Prism443 structure. using the density functional theory (DFT) calculations and MollerPlesset second order perturbation (MP2) calculations.

\section{Calculation Methods}

To locate the low-lying energy structures of neutral water undecamer. we employed the Becke-3 parameters exchange and Lee-Yang-Parr correlation functionals (B3LYP) method by geometry optimization. The $6-311++\mathrm{G}^{* *}(\mathrm{sp})$ basis set with $5 \mathrm{~d}$ components was used, where diffuse $\mathrm{sp}$ basis function for heavy oxygen atoms was added. These B3LYP calculation methods have been widely used to predict the vibrational frequencies and thermodynamic quantities as
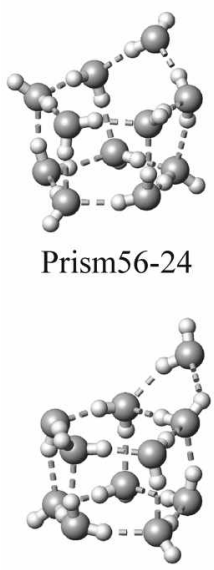

Prism55+1
Prism56-24

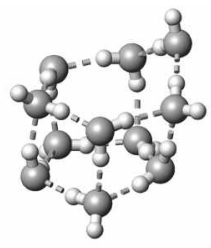

Prism56-13

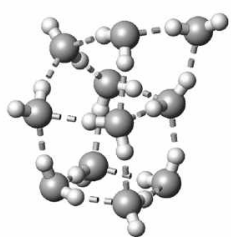

Prism56

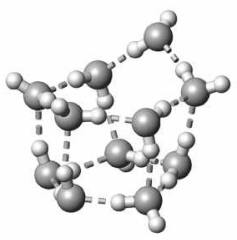

Prism56-134

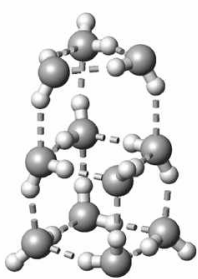

Prism443
Figure 1. Six structures of neutral water undecamer 
Table 1. Interaction energies and geometrical parameters of neutral water undecamers, $\left(\mathrm{H}_{2} \mathrm{O}\right)_{11}$

\begin{tabular}{|c|c|c|c|c|c|c|c|c|c|c|}
\hline Cont. & $-\Delta E^{\text {BзLYP }}$ & $-\Delta E^{\mathrm{MP} 2}$ & $\sharp \mathrm{HB}$ & $\# \mathrm{dda} a$ & $\tau(O O)_{k v}$ & $\angle(O O O)_{\text {min }}$ & $\mathrm{A}$ & B & C & $\mu$ \\
\hline Pт56-24 & 110.81 & 11565 & 16 & 0 & 2.788 & 84.1 & 0.495 & 0.446 & 0.385 & 2.65 \\
\hline Pt56-13 & 110.42 & 115.34 & 16 & 0 & 2.791 & 82.8 & 0.498 & 0.446 & 0.378 & 2.43 \\
\hline Pт56-134 & 110.40 & 115.32 & 16 & 0 & 2.791 & 82.3 & 0.500 & 0.442 & 0.383 & 3.11 \\
\hline PT $55+1$ & 108.77 & 114.47 & 17 & 2 & 2.820 & 57.7 & 0.540 & 0.402 & 0.373 & 2.89 \\
\hline Pт56B & 108.74 & 114.96 & 17 & 2 & 2.809 & 74.5 & 0.605 & 0.412 & 0.371 & 3.44 \\
\hline $\mathrm{PT} 443$ & 105.79 & 112.47 & 18 & 3 & 2.827 & 55.1 & 0.716 & 0.365 & 0.363 & 1.81 \\
\hline
\end{tabular}

Binding energies are in kcal mol, distances in $\AA$, angles in degree, and dipole moment ( $\mu$ ) in debye (D). Fddaa is the number of "ddaa" -type (double proton donor and double acceptor) water molecules. A. B and C are rotational constants (in GHz).

well as binding energies of many and various aqueous clusters. $^{6-1630}$ The B3LYP-predicted vibrational frequencies of water clusters have been especially studied and effectively compared with the experimental outputs. The single point MP2 calculations with the same basis set were done to find a more accurate comparison.

\section{Results and Discussion}

Six structures of W11 are shown in Figure 1. Nomenclature of Prism conformers is noted in reference 8 . Clusters with skeletons of Prism56-ij (Pr56-ij). Prism56 (Pr56 ). Prism55 $+1(\operatorname{Pr} 55+1)$ and Prism443 (Pr443) have 16,17, 17 and 18 HBs. respectively. These skeletons have different HB-interaction frameworks. The binding energies and geometrical parameters are listed in Table 1. It should be noted that the lowest-energy conformer is Prism56-24 which was predicted by Lee et $a l^{8}$

The skeletal shape of Pr56-ij is known to have 20 conformers depending on their $\mathrm{H}$ atom orientations. ${ }^{\delta}$ Since the $\mathrm{H}$ atoms tend to be less clustered (with dangling $\mathrm{H}$ atoms separated), the lowest energy conformer was predicted to be Prism56-24. This is in good agreement in the results in Table 1. Skeletal shapes of Prism56 and Prism 443 are slightly higher in energy than the lowest energy conformer of Prism56-24. Pr56 and Pr443 conformers have more HBs than Pr56-24 as listed in Table 1. but they should have considerable angular strains. A second lowest energy skeletal structure is Prism56 where a cyclic pentamer and an open-book hexamer are fused into a prism-shape. Prism56 conformers are stable among undecamers in Table 1 , and the next stable conformers are Pr55+1 and Pr56. which are isoenergetic. Prism 443 confomer is the least stable among the four different types of skeletons or among the given six conformers.

The Prism56-24" structure (with same HB helicities for pentagonal and hexagonal rings). which is topologically the same with the most stable W11:Prism56-24 structure (with opposite HB helicities). is nearly isoenergetic to it (within $0.09 \mathrm{kcal} / \mathrm{mol}$ in $\Delta \mathrm{E}_{\mathrm{e}}$ and $\Delta \mathrm{E}_{\mathrm{i} j}$ ). ${ }^{8}$ These helicities have been discussed in the relative stabilies of other aqueous clusters: neutral water octamer $\left(D_{-\mathrm{d}}\right.$ and $\left.S_{4}\right)$. water decamer (Prism55 and Prism55"). ${ }^{7}$ dodecamer (Prism444 and Prism444". Prism66 and Prism66"). ${ }^{8}$ electron-bound water octamer (Cd and $\left.\mathrm{Cd}^{\prime \prime}\right)^{\mathrm{l}_{1}}$. and so on.
Table 1 lists the geometric parameters (the average $\mathrm{O}-\mathrm{O}$ distances of interacting water molecules. the minimum $\mathrm{O}-\mathrm{O}$ $\mathrm{O}$ angle and the rotational constants) and dipole moments. In general, the less-HB interaction systems have shorter $\mathrm{O}-\mathrm{O}$ distances. and vice versa. Especially. Pr55+1 and Pr443 have snall $\mathrm{O}-\mathrm{O}-\mathrm{O}$ interaction angles and large $\mathrm{O}-\mathrm{O}$ interaction distances. Pr56-24 has short $\mathrm{O}-\mathrm{O}$ interaction distance and large $\mathrm{O}-\mathrm{O}-\mathrm{O}$ interaction angle. The number of "ddaa"-type water molecules (dd: double proton-donor, aa: double protonacceptor) in Table 1 is related to the characteristic feature representing condensed neutral water in each water molecule is coordinated by four water molecules. resulting in almost all "ddaa: type water molecules in aqueous and solid pahses. Pr55+1. Pr56 and Pr443 have two. two and three "ddaa"țpe water molecules. respectively:

\section{Conclusion}

Based on the B3LYP/6-311++G**(sp) and MP2//B3LYP/ $6-311++\mathrm{G}^{* *}(\mathrm{sp})$ calculations. the lowest energy conformer of the undecamer is Prism56-24 (a fused structure by cyclic water pentamer and hexamer). followed by Prisn 56-24". Thus. this clearly demonstrates that the strictures reported by three groups ${ }^{13-15}$ are not the lowest energy structure. This information would be very critical when the energy of the neural undecamer is compared with that of the ionized or electron-bound water undecamer. Among the clusters with the same and opposite HB helicities. the latter tends to be slightly more stable. Among the nearly isoenergetic conformers with the same skeleton of Prism56. dangling $\mathrm{H}$ atoms tend to be separated as much as possible. and so the structure with less clustered dangling $\mathrm{H}$ atoms tend to be more stable. The second low energy skeleton is Prism56p. The important factors for stabilities of water undecamer are more effective and less-strained $\mathrm{HB}$ interactions. less clustered dangling $\mathrm{H}$ atoms. opposite HB helicities in the same fused frames.

Acknowledgments. This work was supported by KISTEP (CRI). The author would like to thank Prof. K. S. Kim for helpful discussions.

\section{References}

1. (a) Pimental. G. C.: Sederholm. C. H. J. Chom Phys. 1956. 24. 639. (b) Fredin. L.: Nelander. B.: Riblegard. G. J. Chem. Plhs. 1977. 66. 4056. (c) Page. R. H.; Frey, J. G.: Shen, Y.-P.; Lee, Y. T. 
Chem. Phys. Letr. 1984, 106. 373. (d) Coker. D. F; Miller R. E: Watts. R. O. J. Ghem. Phis. 1985. 82. 3554. (e) Dyke. T. R.: Muenter. J. S. J. Chem. Phis. 1972. 57. 5011. (t) Curtiss. L. A.: Frurips. D. L.: Blander. M. Chem. Phys. Lett. 1978. 54. 575. (g) Pugliano. N.: Savkally. R. I. Science 1992,257. 1937

2. (a) Liu. K.: Brown, M. G.: Carter C : Saykally: R. J.: Gregory J. K.: Clary, D. C. Natture 1996, 381. 501. (b) Pribble. R. N.: Zwier. T. S. Scrence 1994. 265, 75, (c) Gruenloh. C. J.: Carney. J. R.: Hagemeister. F. C.: Arrington. C. A.: Zwier. T. S. J. Chem. Phns. 1998. 109. 6601. (d) Huisken. F.: Kaloudis. M.: Kulcke. A. J. Chem. Phns. 1996, 104 17. (e) Buck, U.: Ettischer 1:- Melzer M. Buch, V.: Sadlej. I. Phys. Kev Lett. 1998. 80. 2578. (f) Buck, U: Huisken. F. Chem. Rev 2000, 100, 3863. (g) Nauta, K.: Miller, R. E. Science 2000. 287.293.

3. (a) Morokuma. K.: Pederson. L. J. Chem. Ptns. 1968. 48. 3275. (b) Kollman. P. A.: Allen. L. C. J. Chem. Phys. 1969.51.3286.

4. Del Bene. J.: Pople. J. A. I Chem Phis. 1969. 4. 426: J. (Them. Phvs. 1970,52. 4858.

5. Kim, K. S.: Dupuis. M. Lie, G. C.: Clementi. E. Chem. Phns. Lett. 1986. 131. 451 .

6. (a) Kim. J.: Kim. K. S. J. Chem. Ptns. 1998. 109.5886. (b) Kim. J.: Majumdar. D.: Lee. H. M.: Kim. K. S. J. Chem. Phys. 1999. 110.9128

7. Lee, H. M:s Suh. S. B.: Lee, I. Y.: Tarakeshwar. P.: Kim, K. S. J. Chem Phys 2000. HI2.9759;2001, 114,3343.

8. Lee, H. M.: Sulh. S. B: Kim, K. S. J. Chem. Phvs 2001 , IH. 10749: 2001. 115.7331.

9. (a) Mhin. B. J.: Kim. H. S.: Kim. H. S.: Yoon. J. W. Kim. K. S. Chem. Ptns. Lett 1991. 176.41. (c) Kim. K. S.: Mhin. B. J.: Choi. U.-S. Lee. K. J. Chem. Phws. 1992.97.6649. (d) Mhin. B. J.: Lee. S. I.: Kim. K. S. Phys Rev A 1993 18. 3764. (e) Mhin. B. J: Kim. J.: Lee. S.: Lee, J. Y.: Kim. K. S. J.Chen. Phss 1994 100. 4484. (f) Kim. J.: Mhin. B. J.: Lee. S. J: Kim. K. S. Chem. Phys. Lett. 1994. 219. 243. (g) Kim. J.: Lee. J. Y.: Lee. S.: Mhin. B. J.: Kim. K. S. J. Chem. Plys. 1995. 102.310

10. (a) Graf. S.: Mohr. W.: Leutwyler. S. J. Chem. Phws. 1999. IIO. 7893. (b) Kryachko. E. S. Chem. Phys. Lett. 1997. $272,132$.

11. Franken. K. A.: Jalaie. M.: Dykstra. C. E. Chem. Ptys. Lett. 1992. 198. 59 .

12. (a) Fowler. J. E.: Schaeter III. H. F. J. Am. (Them. Soc. 1995. 117. 446. (b) Klopper, W: Luthi. H. P. Afol Plns. 1999, 96.559.

13. Niesse I. A.: Mayne. H. R. J. Comp. Chem. 1997. 18, 1233.

14. Wales. D. I. Hodges. M. P. Chem. Phns. Lett 1998. 286.65.

15. (a) Sadlej. J. Chem. Plns. Lett 2001. 333. 485 (b) Sobolewski. A. L.: Domcke. W. Phys. Chem them. Phs. 2003. 5. 1130.

16. (a) Feller. D.: Glendening. E. D.: Kendall. R. A.: Peterson. K. A. J. Chent Phys 1994. 100. 4981. (b) Glendening. E. D.: Feller D. J. Phws Chem. 1995. 99. 3060. (c) Feller D. Glendening. E. D: Wooin. D. E. J. Chem. Phws 1995.103 .3526 . (d) Feller. D. J. Plys. Chem. A 1997, 101.2723, (e) Kim. J.: Lee. S.: Cho. S. J.: Min. B. J. Kim. K. S. J. Chem. Phys. 1995. 102.839. (t) Lee. S.: Kim. J.: Park. J. K.: Kim. K. S. J. Phys. Chem. 1996. 100.14329. (g) Lee, H. M.: Kim. I.: Lee. S; Mhin. B. I.: Kim.. K. S. J. Chem. Phys. 1999, HI. 3995

17. (a) Robertson, W. H.: Diken, E. G.: Price, E. A.: Shin. I.-W: Johnson. M. A. Science 2003, 299, 1367. (b) Baik. I.: Kim. I. Majumdar. D.: Kim. K. S. J. Chem. Phys. 1999.110.9116. (c) Majumdar. D.: Kim. J.: Kim. K. S. J. Chem. Plys. 2000. 112. 101. (d) Kim. J.: Lee. H. M.: Suln. S. B.: Majumdar. D.: Kim. K. S. J. Chem. Phys. 2000, 113. 5259. (e) Lee. H. M.: Kim. K. S. J. Chem. Phys 2001. HH. 4461. (f) Lee, H. M.: Kim. D; Kim, K. S. J. Chem. Plys 2002, 116. 5509. (g) Lee. H. M: Kim. K. S. Afol. Plys. 2002. 100. 875. (h) Ayotte. P. Johnson. M. A. J. Chem. Plys. 1997. 106. 811. (i) Kim. J.: Becker. I. Cheshnovsky. O:
Johnson. M. A. Chent. Phys. Lett. 1998. 297.90. (j) Weber. J. M. Kim, J: Woronowicz. E. A.; Weddle. G. H.: Becker, I: Cheshnovsky. O.: Johnsont. M. A. Chem. Plys. Lett. 2001. 339. 337.

18. (a) Ayotte. P.: Weddle. G. H.: Bailey. C. G.: Johnson. M. A.: Vila. F.: Jordan, K. D. J. Chem. Phts 1999. 110.6268. (b) Bailey, C. G.; Kim, J.: Johnson, M. A. J. Phis Chent 1996. 100,16782 . (c) Ayotte. P.: Bailey, C. G.; Kim, J.; Johnson. M. A. J. Chem. Phns. 1998. 108. 444. (d) Kim. .: Park. J. M.: Oh. K. S.: Lee. T. Y.: Lee. S.: Kim. K. S. I. Chem. Phys. 1997. 106. 10207. (e) Kim. J.: Lee. J. Y: Oh. K. S.: Park. J. M.: Lee. S.: Kim. K. S. Phys. Rst A 1999. 59. R930. (1) Kim. J; Sul, S. B.; Kim. K. S. J. Chem. Phys 1999. 111. 10077 . (g) Lee. H. M.: Suh, S. B.: Kim, K. S. Bull. Konean Chent Soc. 2000. 21. 555. (h) Suh, S. B.; Lee. H. M.: Kim, J.; Lee. J. Y.: Kim. K. S. J. Chem. Phys 2000. 113. 5273. (i) Park. I.: Cho. K.: Lee. S.: Kimn. K. S.: Joannopoulos. J. D. Comput. Materials Sci. 2001. 21. 291. (j) Lee. H. M.: Kiml. K. S. J. Chem. Phos 2002. 177. 706. (k) Lehr. L.; Zanni. M. T.: Frischtorn. C.: Weinkaut. R: Neumark, D. M. Science 1999. 284,635.

19. (a) Kim. K. S: Lee, J. Y: Choi, H. S.: Kim. J.: Jang. J. H. Chent. Phys. Lett 1997. 265. 497. (b) Tarakeshwar. P.: Kimn. K. S. Brutschy. B. J. Chem. Phys. 2001. 114. 1295. (c) Manojkumar. T. K.: Choi. H. S.: Tarakeshwar. P.: Kim. K. S. J. Chem Plys. 2003. 118. 8681 . (d) Kim, K. S.: Lee. J. Y.: Lee, S. J.: Ha. T.-K, Kim, D. H. J. Am. Chent Soc 1994, 116, 7399. (e) Oh. K. S.; Lee C.W: Choi. H. S.: Lee, S. J; Kim. K. S. Org. Lett. 2000, 2. 2679. (f) Ihtn. H.: Yun. S.: Kim. H. G.: Kim. J. K.: Kim. K. S. Org. Lett. 2002. 4. 2897. (g) Yun. S.: Kim. Y.-O.: Kim. D.: Kim. H. G.: lhm. H.: Kim. T. K.: Lee. C.W.: Lee. W. T.: Yoon. J: On. K. S.: Yoon. J.; Park. S.-M K Kim, K. S. (Jhg. Lett. 2003, 5. 471. (h) Yun, S: Ihm, H.: Kim, H. G.: Lee, C.-W.; Banyopadhyay. I.; Oh, K. S.: Gong, Y. J:; Lee, J. W:; Yoon, J.: Lee, H. C.: Kim. K. S. J. Org. Chem 2003. 68. 2467.

20. (a) Scheiner. S. Hydrogen Bonding. Ostord Utwversity Press 1997. (b) Kim. K. S.: Tarakeshwar. P.: Lee. T. Y. Chem. Rev 2000. 100.4145. (c) Tarakeshwar, P. Lee. H. M.; Kim. K. S. In Review's of Hodem Oututhm Chemistry, Sen, K. D. Ed.: World Scientific: Singapore, 2002: pp 1642-1683. (d) Kim. K. S: Sul, S. B.: Kim. J. C.: Hong. B. H.: Lee. E. C.: Yun. S.: Tarakeshwar. P.: Lee. I. Y.: Kim. Y.: Ihm. H.: Kim. H. G.: Lee. I. W.: Kim. I. K.: Lee. H. M.: Kim. D.: Cui. C.: Youn. S. J.: Chung. H. Y.: Choi. H. S.: Lee. C.W. Cho. S. J. Jeong. S. Cho. J.-H.J. Am. Chent Soc. 2002.124. 14268. (e) Hong, B. H.: Lee, J. Y.: Lee, C.W. Kim. J. C.: Bae, S C. Kim, K. S. J. Am. Chem. Soc. 2001, 123. 10748. (f) Hong. B. H.: Bae. S. C.: Lee. C.-W.: Jeong. S.: Kiml. K. S. Science 2001. 294. 348. (g) Kim. K. S.: Oh. K. S.: Lee. I. Y. Proc. Natl Acad. Sci. US.t 2000. 97. 6373. (h) Oh. K. S.: Cha. S.-S.: Kim. D.-H.: Cho, H.-S: Ha. N.-C: Choi, G.; Lee, J. Y:; Tarakeshwar, P; Son, H. S.: Choi, K. Y: Oh, B.-H.: Kim, K. S. Biochemismy $2000,39$. 13891. (i) Kim. K. S.: Kim, D.: Lee. J. Y: Tarakeshwar, P: Oh. K. S. Biochemistry 2002. 11.5300. (i) Tarakeshwar. P.: Kim. K. S. J. Mol. Struct 2002. 615. 227. (k) Tarakeshwar. P.: Choi. H. S.: Kim. K. S. J. Am. Chem. Soc. 2001. 123. 3323, (1) Lin. J.: Frey. P. A. J. Aim. Chent Soc $2000,122.11258$.

21. Frisch. M. J.: Trucks, G. W. Schlegel, H. B.: Gill, P. M. W: Johnson. B. G.: Robb, M. A.: Cheeseman, J. R.: Keith. T. A.: Petersson. G. A.: Montgomery. I. A.: Raghavachari. K.: AlLaham. M. A.: Zakrzewski. V. G.: Ortz. J. V: Forsemant. T. B.: Cioslowski. T.: Stetanov. B. B.: Nanayakikara. A.: Challacombe. M.: Peng. C. Y.: Ayala. P. Y.; Chen, W.: Wong. M. W: Andres. J. L. Replogle. E. S.; Gomperts. R: Martin. R. L.; Fox. D. J: Binkely, J. S.: Defrees. D. J.; Baker. J.; Stewart. J. P.: HeadGordon. M.: Gotzalez. C.: Pople. J. A. Gaussian 94. Rev. A: Gaussianl. Inc.: Pittsburgh. PA. 1995. 